\title{
Analysis of Phytoconstituents of Desmodium Adscendens in Relation to its Therapeutic Properties
}

\author{
Seriki $\mathrm{SA}^{1 *}$, Odetola $\mathrm{AO}^{2}$ and Adebayo $\mathrm{OF}^{3}$ \\ ${ }^{1}$ Department of Human Physiology, Edo University, Nigeria \\ ${ }^{2}$ Department of Human Physiology, Nnamdi Azikwe University, Nigeria \\ ${ }^{3}$ Department of Human Physiology, Bingham University, Nigeria \\ *Corresponding author: Seriki SA, Department of Human Physiology, Edo University, Nigeria. \\ To Cite This Article: Seriki SA. Analysis of Phytoconstituents of Desmodium Adscendens in Relation to its Therapeutic Properties. Am J Biomed \\ Sci \& Res. 2019 - 2(4). AJBSR.MS.ID.000598. DOI: 10.34297/AJBSR.2019.02.000598
}

Received: February 08, 2019 | Published: April 23, 2019

\begin{abstract}
Phytoconstituents are chemical compounds produced by plants through primary or secondary metabolism, generally to help them thrive or thwart competitors, predators, or pathogens. Most medicinal plants are known to derive their characteristic benefits from their phytochemical constituents. The phytochemical research approach is considered effective in discovering bioactive profile of plants of therapeutic importance. The present study considers the Phytochemicals of Desmodium adscendens and how they play important roles in the use of the herb as medicines in the treatment of various disease conditions as antimicrobial agents as well as antioxidants. The ethanolic and aqueous extracts of $D$ adscendens were elucidated to determine the chemical constituents of the plant. Results show that Desmodium adscendens has high content of flavonoids, polyphenols and reducing sugar. Alkaloids, glycosides, saponins, tannins were also present, but not in high concentration like the previous three. The presence of these constituent's accounts for the use of Desmodium adscendens in the management and treatment of muscle cramp, tendon, spinal pain, bronchitis, epilepsy and some central nervous system disorders, rheumatism, jaundice, hepatitis, protection of liver from cirrhosis, asthma, allergic symptoms and eczema. It is also a very potent natural antispasmodic agent.
\end{abstract}

Keywords: Antimicrobal effects; phytochemical constituents; Flavonoids; polyphenols; Reducing Sugar.

\section{Introduction}

Phytochemicals are naturally occurring compounds in plant such as fruits, vegetables, whole grains, beans, nuts and seeds. Many phytochemicals act as antioxidants, neutralizing free radicals and removing their power to create damage.

They are naturally found in plants and are responsible for providing colour, flavour, and aroma to fruits and vegetables, and are biologically active and function to protect plants against invasion, disease, and infection. Research on phytochemicals has become very important considering the widespread use of traditional herbs for treatment not only in Nigeria and Africa, but also, to various extents, all countries of the world. It is therefore not a surprise that a number of drugs in use were developed from plant products [1,2]. Indeed World Health Organization (WHO) estimates that up to 80 per cent of people currently rely mainly on traditional remedies such as herbs for their medicines [3].

In Nigeria, majority of the population in the rural settlements use herbal medicine because they have little or no access to Western or orthodox medicine whereas the medicinal plants are easily accessible. In areas where the people have access to Western medicine, herbal medicine is sometimes chosen over orthodox medicine in management of diseases for other reasons such as affordability of cost of treatment with these drugs compared to orthodox drugs. The herbal medicines are found in abundance at virtually no cost. Due to these reasons, plants will continue to be the source of medical care for the majority of the world's poor particularly those in the tropical areas [4].

Quite a large number of plant species and their derivatives are used in different parts of the world for the treatment of diseases. It is estimated that between 35,000 and 70,000 different species of plants have been used as medicines by various peoples of the world, and at least some 7,000 plant-derived medicinal compounds have been introduced into Western pharmacopoeia. Out of these, only about 120 plant-based drugs coming from 95 plant species are prescribed for use worldwide [3,4].

Due to the increased awareness of the significance of traditional medicine in human and animal healthcare, phytochemicals of some of the herbs used in relation to the conditions they are used to manage is considered worthwhile. 
Desmodium adscendens, a rainforest herb has been traditionally used by the natives for a wide variety of medical conditions including muscle cramp, tendon, spinal pain, bronchitis, epilepsy and some central nervous system disorders. Other uses include rheumatism, jaundice, hepatitis, protection of liver from cirrhosis, asthma (owing to its bronchial-dilating effects), allergic symptoms and eczema. It is also a very potent natural antispasmodic and antihypertensive agent [5].

Other studies have revealed that Desmodium adscendens could also be used in women to manage leucorrhoea (a thick yellowish vaginal discharge usually caused by oestrogen imbalance), vaginal infections, and ovarian inflammations [6]. Also, disorders of the ovary and reproductive tract infections have been treated using extracts from the herb [7]. It has been known to also promote lactation in women. Desmodium adscendens has also been used in treating wounds and sores [8].

\section{Desmodium adscendens plant}

Desmodium adscendens is found commonly in tropical areas of Australia, South America and Africa. The plant grows wild in the rainforest of some South American countries and on the west coast of Africa as well. It is believed to have been used for many years by people native to the areas where it grows to manage several health conditions.

It is an herbaceous, perennial plant which grows up the trunks of trees. The leaves and stems are the medicinal parts. The therapeutic phytochemicals in Desmodium adscendens include alkaloids of the family of indolic alkaloids. The plant contains $4 \mathrm{mg} / \mathrm{kg}$ of alkaloids expressed in tryptamine.

Habitat/Ecology: The plant is found and naturalized in pastures, fields, and waste places, sometimes found on open hillsides and along forest trails up to an elevation of about $500 \mathrm{~m}$ [9].

Leaves: Three-foliolate; stipules obliquely ovate-lanceolate with long attenuate apex and slightly auriculate base, $0.5-1 \mathrm{~cm}$ long, 1.5-3 mm wide, puberulent and pilose to glabrescent on the outer surface, persistent; petiole pilose, $1-3 \mathrm{~cm}$ long; leaf-rhachis similar, 0.3-1 cm long; leaflets elliptic-obovate, (acute to) obtuse and emarginate at apex, cuneate to rounded at base, pilose to essentially glabrous on the upper surface, densely soft pilose on the lower; terminal leaflet $1.7-4.3 \mathrm{~cm}$ long, $0.7-3.2 \mathrm{~cm}$ wide; lateral leaflets $1.3-3 \mathrm{~cm}$ long, $0.7-2 \mathrm{~cm}$ wide.

Inflorescence: Composed of axillary and terminal racemes; rhachides striate to grooved, sparsely to abundantly stiff-pilose and finely puberulent with multicellular and uncinulate hairs; primary bracts ovate-acuminate with long attenuate apex, 3.5-5 mm long, 1.5-2 mm wide, 2 pedicels; secondary bracts absent or, if rarely present, depauperate; pedicels with pubescence similar to that of rhachis, 0.4-1.7 (-2.1) cm long. Flowers usually pink. Calyx 2-lipped; tube minutely puberulent; teeth of both lobes pilose, 2-3 $\mathrm{mm}$ long. Corolla exceeding calyx; standard obovate, shortly clawed, 4-5.5 mm long, 2.5-3.5 mm wide; wings \pm oblong, broader above, slightly auricled, shortly clawed, 3-3.5 mm long, 1-2 mm wide; keel-petals somewhat triangular, truncate at apex, gradually narrowed to a long claw, 3.5-4 mm long, $1 \mathrm{~mm}$ wide.

Fruit: With a stipe 0.5-2 mm long, 1-5-articled; articles \pm obliquely oblong, straight on the upper suture, curved below, constricted about half their width at the isthmi, 3.5-5.5 mm long, 2.5-3 mm wide, uncinulate-pubescent throughout.

Seed: Transversely elliptic, $2.5-5 \mathrm{~mm}$ long, $1.5 \mathrm{~mm}$ wide". Its pharmacological properties have given it an edge over many other herbs as aqueous extract of the leaves has been used for several medicinal purposes [10] (Figure 1).

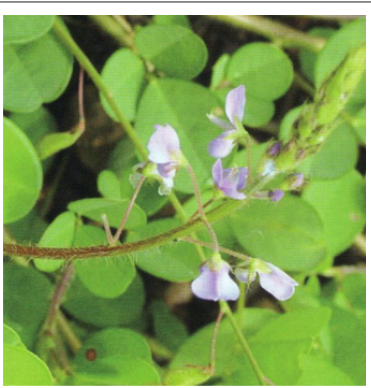

Figure 1: Desmodium adscendens plant.

The efficacy of medicinal plant preparations depends on their active chemical constituents and pharmacological effects. Many of these plants may contain only traces of the medicinal elements; thus, large doses of the preparations have to be administered. Systematic screening of plant preparations is a means of finding their efficacy [11]. An index for assessing the efficacy of a drug or a medicinal plant preparation is the median Effective Dose $\left(\mathrm{ED}_{50}\right)$, which is the dose at which $50 \%$ of individual organisms exhibit the specified effect. The extreme of toxicity resulting in death is assessed by the median Lethal Dose $\left(\mathrm{LD}_{50}\right)$ [12]. These indices provide a convenient way of comparing the potencies and toxicities of drugs and medicinal plant preparations in both experimental and clinical settings [13]. The $\mathrm{LD}_{50}$ of Desmodium adscendens was determined.

\section{Justification of study}

The leaves extract of Desmodium adscendens has been known to be useful in the management and treatment of several disease conditions. Knowledge of the phytoconstituents of the leaves and their percentage composition gives a further insight to the properties that give it the efficacy in the management of such disease conditions.

\section{Materials and Methods}

\section{Collection of Plant Material}

Fresh leaves of Desmodiun adscendens were collected from the forest in the Southern part of Nigeria, and thoroughly rinsed in tap water to remove debris, and was thereafter air dried for about 2 weeks under shade, away from direct sunlight to avoid possible damage to their phytochemical constituents. It was then cut into small pieces and crushed into coarse powder using an electric blender. The powder form of Desmodium adscendens was stored in a sealed bucket until required. 


\section{Preparation of aqueous leaf extract of Desmodium adscendens}

The preparation of the extract was done according to the method by Adeneye et al. [13]. 500g of the powdered leaves of Desmodium adscendens was soaked in $5000 \mathrm{ml}$ tap water in a container stirred and kept for 24 hours. The mixture was then filtered first with a white cotton material, then with a Whatman No. 1 filter paper and funnel into a beaker. Thereafter, the filtrate was evaporated to dryness to get the paste with the help of a water bath. The paste was then scraped using a spatula into plain sample containers, yielding $56.9 \mathrm{~g}$ of the extract. From the yield, a stock solution was prepared at various doses desired by serial dilution of the extract. The diluted extract was preserved in a refrigerator until the time of administration.

\section{Acute toxicity test}

Twenty-four (24) mice of both sexes(male and female)weighing between $2026 \mathrm{~g}$ were purchased from the Animal House of the faculty of Basic medical sciences, University of Calabar, Calabar, Cross River State, Nigeria.

They were randomly grouped into six (6) groups with four (4) in each cage.

The mice were allowed to acclimatize for 7 days. Five (5) doses of the extract $(200 \mathrm{mg} / \mathrm{kg}, 400 \mathrm{mg} / \mathrm{kg}, 800 \mathrm{mg} / \mathrm{kg}, 1200 \mathrm{mg} / \mathrm{kg}$, $3200 \mathrm{mg} / \mathrm{kg}$ ) which was in distilled water were administered orally (per os) to the rats in group 2, 3, 4, and 5 respectively. Group 1 served as the control. Animals were monitored closely during the first 24 hours post treatment for behavioral changes and death due to toxicity. The median lethal dose $\left(\mathrm{LD}_{50}\right)$ was determined according to the method by Kengni et al. [14].

\section{Phytochemical Analysis}

The ethanolic leaf extract of Desmodium adscendens was subjected to phytochemical analysis. $2 \mathrm{~g}$ of the crude extract was weighed and dissolved in $20 \mathrm{ml}$ of distilled. The solution was screened for the presence and absence of alkaloids, flavonoids, tannins, saponins, glycosides, reducing agents, polyphenols, anthraquinones, and phlobatanins following standard methods $[15,16]$.

\section{Test for alkaloids}

Mayer's test: $2 \mathrm{ml}$ of the filtrate and control solution were pipetted into two separate test tubes. To the test tubes were added 3 drops of Mayer's reagent. The solutions were mixed and allowed to stand for $5 \mathrm{~min}$ and then observed for the presence of precipitate and color change.

Wagner's test: $2 \mathrm{ml}$ of the filtrate and control solutions were pipetted into two separate test tubes. To the test tubes were added 3 drops of Wagner's reagent. The solutions were mixed and allowed to stand for $5 \mathrm{~min}$ and then observed for the presence of precipitate and color change.

Dragendorrf's test: $2 \mathrm{ml}$ of the filtrate and control solutions were pipetted into two separate test tubes. To the test tubes were added 3 drops of Dragendorff's reagent. The solutions were mixed and allowed to stand for $5 \mathrm{~min}$ and then observed for presence of precipitate and color change.

\section{Test for tannins:}

I. $2 \mathrm{ml}$ of the filtrate and control solution were pipetted into two separate test tubes. To the test tubes were added 3 drops of $10 \%$ ferric chloride. The mixtures were observed for presence of precipitate and color change.

II. $2 \mathrm{ml}$ of the filtrate and control solution were pipetted into two separate test tubes. To the test tubes were added 3 drops of $10 \%$ lead acetate. The mixtures were observed for presence of precipitate and color change.

\section{Test for flavonoids:}

I. $2 \mathrm{ml}$ of the filtrate and control solutions were pipetted into two separate test tubes. To the test tubes were added 3 drops of $\mathrm{NaOH}$. The mixtures were allowed to stand for $2 \mathrm{~min}$ and then observed for presence of precipitate and color change.

II. $2 \mathrm{ml}$ of the filtrate and control solutions were pipetted into two separate test tubes. To the test tubes were added 3 drops of $\mathrm{NaOH}$ and 3 drops of $0.5 \mathrm{~N} \mathrm{HCl}$. The mixtures were observed for presence of precipitate and color change.

\section{Test for saponnins:}

\section{Emulsifying test}

$2 \mathrm{ml}$ of the filtrate and control solution were pipetted into two separate test tubes. To the test tubes were added 3 drops olive oil and the mixture shaken vigorously. The mixtures were observed for presence of brown emulsion.

\section{Frothing test}

$1 \mathrm{ml}$ of the filtrate and control solution were pipetted into two separate test tubes. To the test tubes were added $4 \mathrm{ml}$ distilled water. The mixture was shaken vigorously and then observed for presence of frothing.

Test for Anthraquinone: $0.1 \mathrm{~g}$ of the crude extract was dissolved in $10 \mathrm{ml}$ concentrated chloroform. The solution was filtered and used for this test. To $5 \mathrm{ml}$ of filtrate and control solution in separate test tubes was added $5 \mathrm{ml}$ ammonia solution. The mixtures were shaken vigorously. The mixtures were observed for presence of precipitate and color change.

Test for Glycoside: To $2 \mathrm{ml}$ of filtrate and control solutions in separate test tubes were added $2 \mathrm{ml}$ of Fehling I and Fehling's II solutions. The solutions were mixed thoroughly and boiled in a water bath for $2 \mathrm{~min}$. The mixture was observed for the presence of precipitate and color change.

Test for Terpenes: $0.1 \mathrm{~g}$ of the crude extract was dissolved in $10 \mathrm{ml}$ concentrated chloroform. The solution was filtered and used for this test. To $1 \mathrm{ml}$ of filtrate and control solutions in separate test tubes were added $1 \mathrm{ml}$ acetic anhydride. The solutions were mixed thoroughly with a glass rod. The test tubes were then placed 
in slanting positions and $1 \mathrm{ml} \mathrm{H}_{2} \mathrm{SO}_{4}$ was added to the side of each test tube into the mixture. The junction of the two liquid layers was observed for the presence of color change.

\section{Results}

The therapeutic phytochemicals in Desmodium adscendens include alkaloids of the family of indolic, alkaloids flavonoids (such as astragalin, cosmosin), soyasaponins (such as dehydrosoyasaponin), and bioamine (tyramine). The plant contains about $4 \mathrm{mg} / \mathrm{kg}$ of alkaloids expressed in tryptamine. Fatty acids are present to a concentration of about $3 \%$, which is relatively rich in unsaturated acids (Table 1).

\begin{tabular}{|l|l|l|}
\hline \multicolumn{3}{|c|}{ Table 1: Phytochemical constituents of ethanolic and aqueous leaves } \\
extracts. \\
\hline Phytochemicals & Ethanolic extract & Aqueous extract \\
\hline Alkaloids & $2.53 \pm 0.01$ & $2.56 \pm 0.02$ \\
\hline Glycosides & $2.30 \pm 0.01$ & $2.45 \pm 0.01$ \\
\hline Saponins & $2.05 \pm 0.01$ & $2.10 \pm 0.01$ \\
\hline Tannins & $0.37 \pm 0.01$ & $0.42 \pm 0.01$ \\
\hline Flavonoids & $10.57 \pm 0.01$ & $8.23 \pm 0.02$ \\
\hline Polyphenols & $14.68 \pm 0.01$ & $13.71 \pm 0.02$ \\
\hline Reducing sugars & $8.73 \pm 0.02$ & $5.70 \pm 0.01$ \\
\hline
\end{tabular}

Each value represents the mean of 3 determinants \pm SEM

The triterpenoid glycosides (and other phytochemicals such as beta-phenylethylamines and tetrahydroisoquinolines) found in Desmodium adscendens are very potent potassium channel agonists. They activate the calcium-dependent potassium ion channels; when potassium ions cross the cell membranes, while the tone in the smooth muscles is maintained.

\section{Discussion and Conclusion}

\section{Discussion}

The present study on $D$. adscendens was carried out to determine the phytochemicals in the leaf of the herb and how they relate to the kind of medicinal benefits the herb is used for. It is also to observe if the plant extract has any toxic effects on the body. This was necessitated by previous scientific reports on the many medicinal benefits of the plant $[5,6,8,11]$.

D. adscendens is normally administered orally for treatment, thus the oral route was chosen in this study. The $50 \%$ lethality estimate was $1,342.32 \mathrm{mg} / \mathrm{kg}$ body weight, an indication that the extract is relatively non-toxic and safe for consumption considering the high LD50 value with reference to research guidelines [17].

Phytochemical screening of Desmodium adscendens leaf extract showed the presence of alkaloids, flavonoids, saponins, tannins, glycosides, polyphenol, and reducing sugar, with polyphenol, flavonoids, and reducing sugar having higher concentrations compared to others.

Flavonoids, which is high in concentration in Desmodium adscendens have been shown to inhibit coagulation, thrombus formation or platelet aggregation, reduce risk of atherosclerosis, reduce arterial blood pressure and risk of hypertension, reduce oxidative stress and related signalling pathways in blood vessel cells, modify vascular inflammatory mechanisms, improve endothelial and capillary function, modify blood lipid levels, regulate carbohydrate and glucose metabolism [18]. This may have accounted for the use of D. adscendens antispasmodic as an antihypertensive agent.

The extract also has high concentration of polyphenols and reducing sugar which are strong antioxidants compared to other phytochemical constituents like tannins, saponins, glycosides and alkaloids. Antioxidants may protect the body's cells from harmful free radicals from cigarette smoke and other environmental contaminants. Free radicals can increase LDL, or "bad" cholesterol, thereby increasing the risk for heart disease.

The flavonoids, apart from mopping up free radicals from the body system, serve to inhibit the pro-inflammatory activities of enzymes involved in free radical production, such as cyclooxygenase, lipoxygenase or inducible nitric oxide synthase.

Polyphenols and Flavonoids have also been reported to jointly have lowering effect on plasma creatinine and urea concentration, which may have caused D. adscendens to lower creatinine and urea concentration thereby protecting the kidney [19].

Alkaloids, glycosides and saponins have antimalarial, antiasthma, anticancer, vasodilatory, antiarrhythmic, analgesic, antibacterial and antihyperglycemic activities. The extract may only needed to be administered in high doses for a patient to derive these benefits since the concentrations of these set of phytochemicals are not as high like flavonoids, polyphenols and Reducing Sugar.

Alkaloids, present in relatively high concentration in D. adscendens, are nitrogen-containing natural compounds having a wide range of pharmacological activities including antimalarial, antiasthma, anticancer, cholinomimetic, vasodilatory, antiarrhythmic, analgesic, antibacterial and antihyperglycemic activities. Alkaloids also possess psychotropic and stimulant activities [20].

Studies have shown that saponins may support the immune system, promote normal cholesterol levels, and support overall wellness [21]. It's foam-like product with water helps it bind with water as well as fats and oils. This means that, in the digestive tract, saponins produce an emulsification of fat-soluble molecules. Specifically, saponins bind to bile acids and help eliminate them from the body, preventing cholesterol from being reabsorbed. Saponins could therefore be described as a "wash away" of various toxins from the body.

Flavonols may reduce dangerous inflammation in the arteries, and may also have positive effects on blood clotting, coronary artery function and insulin sensitivity. Studies have also found that flavonoids inhibit a variety of cancers in animals. Also, insufficient evidence exists to show that high flavonoid intake can reduce human cancer risk that extracts from flavonoid-rich onions provided strong anti-proliferation effects against liver and colon cancer cells. 
Alkaloids, which are a large and structurally diverse group of compounds, have served as scaffolds for important antibacterial drugs like metronidazole and the quinolones. There are natural, semi-synthetic, and synthetic alkaloids of all classes; while some are with direct antibacterial activity and others are with antibioticenhancing activity. Potent examples include CJ-13,136, a novel actinomycete-derived quinolone alkaloid with MICs of $0.1 \mathrm{ng} / \mathrm{mL}$ against Helicobacter pylori, and squalamine, a polyamine alkaloid from the dogfish shark which renders Gram-negative pathogens 16 to $>32$-fold more susceptible to ciprofloxacin [20].

The effects of alkaloids on virulence gene regulatory systems such as quorum sensing, and virulence factors like sortases, adhesins, and secretion systems are also described. The synthetic isoquinoline alkaloid virstatin, for example, inhibits the transcriptional regulator ToxT in Vibrio cholerae, preventing expression of cholera toxin and fimbriae, and conferring in vivo protection against intestinal colonization. This may be the reason D. adscendens is used to treat diarrhea and other infections of the gastrointestinal tract [20].

\section{Conclusion}

The leaf extract of $D$. adscendens extract has an $\mathrm{LD}_{50}$ value of $1342.32 \mathrm{mg} / \mathrm{kg}$. It has high concentration of flavonoids, polyphenols and reducing agents. These are the phytochemicals in Desmodium that have given it the characteristic medicinal properties, and indeed its use as medicines to manage various disease conditions.

\section{Recommendation}

However, further research is needed to determine whether flavonoids work to deliver these benefits, or they must work in combination with other phytochemical to effectively discharge their functions.

\section{References}

1. Ayensu ES (1978) Medicinal Plants of West Africa: Reference Publications Inc, Michigan, USA, pp. 149-152.

2. Nergard CS, Diallo D, Inngjerdingen K, Michaelsen TE, et al. (2005) Medicinal use of Cochlospermum tinctorium in mali anti-ulcer-, radical scavenging- and immunomodulating activities of polymers in the aqueous extract of the roots. Journal of Ethnopharmacology 96(1-2): 255-269.

3. Lewington A (1990) Plants for people: The Natural History Museum Cromwell Road, London, pp. 135-167.

4. Principe P (1989) The Economic Value of Biological Diversity Among Medicinal Plants; Organization for Economic Co-operation and Development, Environmental Monograph, Paris, pp. 140.
5. Taylor L (2005) The healing power of rainforest herbs. Square One Publishers, USA, pp. 528.

6. Guarin NG (1996) Plantas medicinais do Estado do Mato Grosso. Associação Brasileira de Educação Agrícola Superior, p. 31.

7. Barreto GS (2002) "Effect of butanolic fraction of Desmodium adscendens on the anococcygeus of the rat." Braz J Biol 62(2): 223-230.

8. Addy ME (1997) Some Secondary Plant Metabolites in Desmodium Adscendens and their effects on Anaihidonic Acid Metabolism. Prostaglandins Leukotrienes Essent Fatty Acids 47(1): 85-91.

9. Smith, AC (1985) Flora Vitiensis nova: a new flora of Fiji. National Tropical Botanical Garden, Lawai, Kauai, Hawaii 3: 758.

10.Adjanohoun E (1998) Contribution to ethnobotanical and floristic studies in the People's Republic of Congo. Traditional Medicine and Pharmacognosy Suppl 3: 428 .

11. Evans WC (2002) Trease and Evans Pharmacognosy, 15th edition, WB Sanders London, pp. 214-393, 419.

12. Osbourne Q (1998) Biochemical Toxicology of Desmodium adscendens. Department of Biochemistry, University of Ghana, Legon.

13. Adeneye AA, Olagunju JA, Elias SO, Olatunbosun DO, et al. (2008) Protective activities of the aqueous root extract of Harungana madagascariensis in acute and repeated acetaminophen hepatotoxic rats. International Journal of Applied Research in Natural Products 1(3): 29-42.

14. Kengni F, Tala DS, Djimeli MN, Fodouop SPC, Kodjio N, Magnifouet HN, Gatsing D (2013) In vitro antimicrobial activity of Harungana madagascriensis and Euphorbia prostrata extracts against some pathogenic Salmonella sp. International Journal of Biological and Chemical Science 7(3): 1106-1118.

15. Trease, G.E and Evans W.C. (1984). Pharmacognosy 12th Ed. Bailliere Tindal, London, pp. 622.

16. Harbourne, J.B (1998). Phytochemical Methods. 3rd edition. Chapman and Hall London, pp. 198.

17. Ermst E (2005) The efficacy of herbal medicine- an overview. Fundam Clinical Pharmacology 19(4): 405-409.

18. Vèronique $H$, Christine $M$ (2012) Evidence for a protective effect of polyphenols-containing foods on cardiovascular health: an update for clinicians. Therapeutic Advances Chronic Diseases 3(2): 87-106.

19. Takako Y, Eun JC, Takako N (2003) Influence f Green Tea Polyphenol in Rats with Argini-induced Renal Failure. Journal of Agricultural and Food Chemistry 51(8): 2421-2425.

20. Cushnie TP, Cushnie B, Lamb AJ (2014) Alkanoids: An Overview of their antibacterial, Anti-biotic enhancing and Antivirulence Activities. International Journal of Antimicrobial Agents 44(5): 377-386.

21. Rajput ZI, Hu SH, Xiao CW, Arijo AG (2007) Adjuvant Effects of Saponins on Animal Immune Responses. J Zhejiang University Science B 8(3): 153-161. 